\title{
ESTUDO DO APARECIMENTO DO HABITO DE PICA E DESEJOS EM GESTANTES
}

\author{
Maria Solange Guarino Tavares *
}

\section{1 - INTRODUÇAO:}

Os hábitos de alimentação humana estão intimamente ligados às suas crenças culturais e religiosas, tradições e tabus.

Na literatura antropológica, é conhecida como geográfica a prátíca da ingestão de substâncias, como barro e goma. Alguns elementos de tribos negras e indígenas, por exemplo, foram definidos como "comedores de lama".

O fator da segregação racial - como elemento chave para manutenção de hábitos e costumes trazidos da cultura africana - é mencionado em estudos realizados nos Estados Unidos da América do Norte. Edward et alli (1954), estudando 150 mulheres negras, com o objetivo de verificar a influência dos tabus, crenças, tradições e costumes nos hábitos dietéticos de mulheres grávidas e não grávidas, encontrou 55 com manifestações de desejos e, entre estas $67,3 \%$ tiveram-nos durante a gestação.

Durante o período gestacional ou não as mulheres podem apresentar o hábito de Pica ou Malácia, que é o gosto por alimentos esdrúxulos, condimentos raros e substâncias estranhas (REZENDE, 1959), ou por substâncias potencialmente prejudíciais, tais como o barro ou a goma ELLIOTT (1968). Podem ainda, apresentar Desejos que são definidos como uma urgente e imperativa cobiça por determinados tipos de alimentos POSNER et alli (1957).

A incidência de Pica é discutida, sendo que os achados a respeito são muito variados, como se observa nas publicações de Harries, Hugles e Toggart (cit REZENDE, 1969).

* Auxiliar de Ensino junto à disciplina de Enfermagem Obstétrica e Ginecológica. Departamento de Enfermagem Geral e Especializada. E.E.R.P.U.S.P. 
Os dois primeiros referem a incidência deste hábito entre as gestantes estudadas. No entanto, o terceiro não o encontrou em seu estudo ,mas coloca a ressalva de que isto pode ser devido ao fato de as pacientes negarem o hábito, por vergonha ou timidez.

São poucas as informações quanto à variedade dos Desejos. Contudo, encontram-se algumas citações sobre as causas do hábito.

Por outro lado, os tipos de Pica têm sido mencionados em detalhes POSNER, (1957) e, em geral, seu aparecimento está relacionado às gestações anteriores e ao fato de a paciente ter algum familiar ou conhecido que o apresente. Parece ser mais frequente em mulheres da raça negra que nas de outras raças.

Tanto a Pica como os Desejos parecem estar mais ligados às mulheres grávidas que as não grávidas e ser mais incidente no segundo trimestre da gestação GLADFELTER, (1960).

Enontram-se referénias sobre a influência da Pica na mãe e no feto. A presença de resíduos no líquido amniótico e no Vérnix caseoso denso podem ser relacionados a esse hábito, bem como 0 indice baixo de APGAR no primeiro minuto após o nascimento.

Diante do exposto, sentimos a necessidade de investigar, em nosso meio, o aparecimento dos hábitos de Pica e Desejos entre gestantes, desde que este fato, embora do conhecimento popular ainda não tenha sido sistematicamente estudado dentro da cultura brasileira.

Deste modo, pretendemos:

a) verificar a incidência de Pica e Desejos numa determinada região;

b) estudar entre os casos existentes quais os diferentes tipos de Pica e Desejos apresentados pelas gestantes.

\section{$2-M E T O D O L O G I A:$}

Este trabalho foi realizado no Ambulatório Pré-natal do Hospital das Clínicas da Faculdade de Medicina de Ribeirão Preto.

A coleta de dados foi feita de 10 de julho a 9 de agosto de 1973. Foram realizadas entrevistas diáriàs com as gestantes, de segunda a sexta-feira, no peroído das 8 às 12 horas.

\subsection{POPULAÇÃO:}

Durante o período de um mês, entrevistamos 120 gestantes, residentes ou não em Ribeirão Preto. 
Incluíram-se na população somente aquelas que procuravam 0 Ambulatório de atendimento Pré-natal para a primeira consulta, pela primeira vez.

\subsection{PROCEDIMENTOS E TECNICA:}

As consultas médicas foram marcadas antecipadamente pela triagem do Ambulatório Pré-natal.

As gestantes foram encaminhadas ao local da entrevista, após terem sido pesadas e medidas, sem que tivesse recebido qualquer orientação anterior. Foram entrevistadas individualmente, em local privativo.

Utilizamos a técnica de entrevista com formulário testado previamente.

Este formulário constou de três partes principais:

a) dados pessoais (cor, idade, estado civil e parturição).

b) condições sócio-econômicas.

c) hábitos dietéticos que definem os diferentes tipos de Pica e Desejos.

\section{3: DEFINIÇÃO DE TERMOS:}

Neste estudo foram utilizados alguns vocábulos que serão definidos operacionalmente, a seguir:

Pica: - gosto por substâncias estranhas que podem ser prejudiciais à gestante e que, em nosso meio, não estão incluídas nos hábitos alimentares.

Desejos: - o que define desejo é:

a) o fato de essas substâncias ingeridas sem as caracteristicas normais de alimentação. Ex.: desejo de comer sal de cozinha puro.

b) o fato de querer comer o alimento preparado por outras pessoas. Ex.: comer feijão preparado pela sogra.

c) o fato de usar uma substância que não usava fora da gestação. Ex.: mascar chicletes.

Também foi considerada desejo, a vontade de fumar expressa pela gestante, e que não era hábito anterior a este estado.

Gestante: mulher que concebeu e desenvolve dentro de si um novo ser.

Gestação: estado peculiar da mulher que gerou durante o qual desenvolve-se o produto conceptual. 
Frutas citricas: limão, laranja, abacaxi, tamarindo, tangerina, uva, manga verde, maçã, pitanga, cajamanga.

Frutas não citricas: banana, abacate, melancia, jaboticaba, pera, caqui, manga, goiaba, jatobá, ameixa, pêssego, mamão.

Leite e derivados: queijo, requeijão, manteiga.

Bebidas e sucos: cerveja, vinho branco, vitamina, suco de laranja, suco de limão, champanhe, batida de coco, martini.

Salgados: sanduíche, pastel, quibe, coxinha, esfirra.

Doces: bolo, pudim, sorvete, bala favo de mel, biscoito, melado de cana de açúcar, doces em geral.

Verduras: abobrinha, acelga, alface, agrião, almeirão, beringela, chicória, brócolos, couve-flor, espinafre mostarda, repolho, tomate. verde.

Cereais: mandioca, batata doce, batata inglesa, arroz, milho

Legumes: abóbora, beterraba, cenoura, chuchu, ervilha, feijão, quiabo, vagem.

Massas: macarrão, pão caseiro, polenta.

Sopas: de cebola, mandioquinha, macarrão com creme, canja de galinha.

Diversos: pato assado, feijoada, azeitona, pimenta, comida dos vizinhos, feijão feito pela sogra, comida feita pela mãe, vinagre, chicletes, maionese, sal puro, dobradinha, comida de pensão.

3 - RESULTADOS:

Os resultados apresentados referem-se às 120 gestantes estudadas em um total de 417 gestações.

A maioria da população $(61,7 \%)$ era de cor branca e a minoria $(38,4 \%)$, não branca. $77,6 \%$ das gestantes eram jovens - faixa etária de 15 a 30 anos. A maioria $(75,9 \%)$, casadas.

Quanto ao nível sócio-econômico e cultural das gestantes obtivemos os seguintes resultados:

a) o nivel de instrução das gestantes variou do curso primário incompleto ao secundário incompleto $(\mathbf{7 4 , 2} \%)$.

b) entre os responsáveis pelas famílias $(56,8 \%)$, predominou a atividade manual assalariada. Em relação às gestantes, $81,6 \%$ não exercem atividades fora de casa e um pequeno número $(18,3 \%)$ se distribuiu igualmente entre ser empregada doméstica e exercer outras atividades do nível manual assalariado.

c) a renáa per-capita da maioria das famílias das gestantes é baixa. $85,0 \%$ chegam a ganhar no máximo $\mathrm{Cr} \$ 200,00$ mensais. 
O aparecimento dos hábitos de Pica e Desejos são relacionados na tabela a seguir:

TABELA I

Aparecimento do hábito de Pica, segundo aparecimento de Desejos

\begin{tabular}{cccc}
\hline $\begin{array}{c}\text { Pica } \\
\text { Desejo }\end{array}$ & Têm & $\begin{array}{c}\text { Não } \\
\text { Têm }\end{array}$ & Total \\
\hline Têm & 6,7 & 78,3 & 85,0 \\
Não tem & 1,7 & 13,3 & 15,0 \\
\hline Total & 8,4 & 91,6 & 100,0 \\
\hline
\end{tabular}

De acordo com a tabela acima podemos observar que a minoria das gestantes $(8,4 \%)$ apresentaram o hábito de Pica. Quanto aos hábitos de Desejos, cerca de $\mathbf{8 5 , 0 \%}$ destas gestantes apresentaramnos durante a gestação. Os hábitos ocorrem concomitante em 6,7\% dos casos.

TABELA II

Frequência e percentual dos 12 tipos de Pica encontrados

\begin{tabular}{lrr}
\hline Tipos de Pica & F & $\%$ \\
\hline arroz cruz & 3 & 25,0 \\
milho cruz & 1 & 8,3 \\
carne crua & 1 & 8,3 \\
pele de porco crua & 1 & 8,3 \\
terra seca & 3 & 25,0 \\
barro & 2 & 16,7 \\
tijolo & 1 & 8,3 \\
& & \\
\hline Total & 12 & 100,0 \\
\hline
\end{tabular}

Sigla: $\mathbf{F}=$ freqüência

$\%=$ porcentagem

Entre as 120 gestantes, encontramos 10 com o hábito de Pica que variou de acordo com a tabela acima. 
Os tipos de Pica mais frequentes nestas gestantes foram: comer arroz cru, terra seca e/ou barro. Entre as gestantes estudadas, 102 apresentaram Desejos, que são relacionados em 350 tipos na tabela III.

TABELA III

Freqüência e percentual de 350 tipos de Desejos encontrados

\begin{tabular}{lrr}
\hline Tipos de Desejos & F & $\%$ \\
\hline Frutas citricas & 78 & 22,3 \\
Frutas não cítricas & 38 & 10,9 \\
Carne de porco & 5 & 1,4 \\
Carne de vaca & 8 & 2,3 \\
Frango & 12 & 3,4 \\
Peixe & 3 & 0,9 \\
Figado & 4 & 1,1 \\
Leite e derivados & 14 & 4,0 \\
Bebidas e sucos & 29 & $\mathbf{8 , 3}$ \\
Salgados & 24 & $\mathbf{6 , 9}$ \\
Doces & 38 & 19,4 \\
Verduras & 7 & 2,0 \\
Cereais & 7 & 2,0 \\
Legumes & 12 & 3,4 \\
Massas & 14 & 4,0 \\
Sopas & 3 & 0,9 \\
Fumo & 4 & 1,1 \\
& &
\end{tabular}

Os desejos mais frequentes foram por frutas cítricas, doces e/ou frutas não cítricas.

4 - DISCUSSÃO:

Pelos resultados obtidos, observamos que a população na sua maioria era branca, adultas, jovens, casadas, residentes principalmente na zona urbana, seja da cidade de Ribeirão Preto ou fora dela. Essa população quase não apresentou instrução acima do secundário e teve uma pequena porcentagem de analfabetos. A maioria não exercia atividades fora de casa $(81,6 \%)$. 
Tendo-se em vista o tipo de ocupação da maioria dos responsáveis pela família das gestantes ter sido de manuais assalariados, era de esperarmos que a renda per-capita fosse, baixa, como ocorreu, não ultrapassando um salário de Cr\$200,00 mensais.

Ao estudarmos o aparecimento dos hábitos de Pica e Desejos na população total, verificamos que, de modo geral, as gestantes apresentaram mais o hábito de Desejos que o de Pica. O número de gestantes que não apresentaram qualquer tipo de hábito foi, praticamente reduzido $(13,3 \%)$.

Pudemos, através do $x^{2}$, mostrar que não há associação entre as variáveis Pica/Desejos apresentados pelas gestantes.

Houve interesse em verificarmos entre os hábitos de Desejos e Pica, quais os alimentos ou substâncias mais freqüentemente procurados.

Em relação ao hábito de Desejos encontramos em primeiro luagr Desejos por frutas cítricas, a seguir por doces e em terceiro por frutas não cítricas. As demais substâncias apareceram em menor porcentaegm e estão especificadas na tabela III. Quanto ao hábito de Pica, encontramos primeiramente uma maior procura por arroz cru e terra seca, a seguir por barro (Tabela II).

Relacionando os dados obtidos, verificamos que a procura de substâncias parece indicar uma necessidade orgânica das gestantes, porquanto as mais ingeridas foram aquelas que contêm sais minerais, ferro, vitaminas, glicose, etc. Dada a renda baixa supõem-se que estas gestantes tenham má alimentação e baixa ingestão destes alimentos básicos, necessários às atividades orgânicas. Por exemplo, parece contraditória a procura de frutas cítricas e doces, no entanto o açúcar é muito importante como fonte energética e as frutas como fontes vitamínicas. Outro exemplo é a procura por arroz cru e terra que também lembram-nos a necessidade de ingestão de substâncias energéticas, protéica e de ions, principalmente de ferro.

Essa hipótese parece reforçada quando nos lembramos que o próprio estado gestatório leva a maiores exigências orgânicas. Há ainda $o$ fato de que entre as gestantes estudadas, a maioria (70.8\%) tiverem várias gestações anteriores, umas próximas das outras, podendo isso ter contribuído para um maior desgaste físico.

Outro aspecto a ser lembrado seria a procura de alimentos estar relacionada às dificuldades das gestantes em adquirí-los, em razão de sua situação econômica e aproveitando-se do período gestatório para exigí-los.

Podemos ainda levantar a possibilidade destas gestantes serem portadoras de parasitoses intestinais, o que as levariam a uma pro- 
cura maior de substâncias que contenham ferro, como se observa em crianças portadoras de verminoses e que apresentam o hábito de Pica.

Conquanto todas estas possibilidades devam ser estudadas e analisadas mais cuidadosamente, não podemos esquecer aquelas gestantes que nas mesmas condições não apresentaram qualquer tipo de hábito. Existirão outros fatores como a ansiedade, por exemplo, determinando o aparecimento de hábitos de Desejos e Pica?

\section{5 - CONCULSAO:}

Este trabalho não é conclusivo e nem se pretende que tenha sido um estudo exaustivo do assunto. Variáveis como raça, classe social, religião, tabus. ou crenças não puderam ser estudadas por falta de amostra suficiente. $O$ que pretendíamos na realidade era um levantamento da situação, que nos oferecesse subsídios para estudos mais detalhados do assunto. Deste modo, este trabalho se constitui quase que como uma preliminar para outros que venham a esclarecer as dúvidas levantadas e pesquisar outros aspectos não aventados no presente estudo.

\section{$6-B I B L I O G R A F I A$}

COFFIN, M. A. - Nutritional needs and responses. In: - Nursing observations of the young patient. Dubuque, Iowa, WM. C. Browr., (Foundation of nursing series) p. 21-43, 1972.

EDWARDES, C. H. et al - Odd dietary practices women. J. Amer. Diet., 30 (10): 976-981.

ELLIOTT, J. M. - Pica and pregnancy. The nursing clinicas of North America, Philadelphia, 3 (2): 299-305, 1968.

GLADFELTER, J. E. \& BLACK, B. - The study of pica and food preferences in a post-partum. Rep. Biolog. Med, Texas, 18 (2) : 202-204.

NOBMANN, E. D. \& ADAMS, S. - Survey of changes in food habits during pregnancy. Publ. Healt. Rep., 85 (12): 1121-1127, 1970.

PEREIRA, L. - O magistério primário numa sociedade de clsses. Sáo Paulo, Pioneira, 1969.

POSNER, L. B.; Mc COTTRY, C. M.; POSNER, A. C. - Pregnancy craving and pica. Obstetrics and Gynecology, 9 (3): 270-272, 1957.

PIOVESAN, A. - Antropologia (apostila mimeografada, Fac. de Higiene e Saúde Pública da U.S.P., 1959).

REZENDE, J. - Repercussão da Gravidez sobre o organismo. In: Obstetricia, 2. ed. Rio de Janeiro, Guanabara, Koogan, p. 124-142, 1959.

WOODY, R. H. - Controlling pica via an enviromental psycho-hehaviorial strattegy with special reference to lead poisoning. J. Ser. Heal., 41 (12): 548-555, 1971. 